\title{
BORA regulates cell proliferation and migration in bladder cancer
}

\author{
Songtao Cheng ${ }^{1,2,3 \dagger}$, Tianchen Peng ${ }^{1,3+}{ }^{\dagger}$, Xiaolu Zhu ${ }^{4}$, Fenfang Zhou ${ }^{1,3}$, Gang Wang ${ }^{5,6,7}$, Lingao Ju $u^{5,6,7}$, \\ Yu Xiao $13,5,6,7$, Xuefeng Liu ${ }^{2}$ and Xinghuan Wang ${ }^{1 *}$ (1)
}

\begin{abstract}
Background: Bladder cancer is having a gradually increasing incidence in China. Except for the traditional chemotherapy drugs, there are no emerging new drugs for almost 30 years in bladder cancer. New potential therapeutic targets and biomarkers are urgently needed.

Methods: BORA is the activator of kinase Aurora A and plays an important role in cell cycle progression. To investigate the function of BORA in BCa, we established BORA knockdown and overexpression cell models for in vitro studies, xenograft and pulmonary metastasis mouse models for in vivo studies.

Results: Our results indicated that BORA was upregulated in human bladder cancer (BCa) compared to the normal bladder and paracancerous tissues at transcriptional and translational levels. We found that BORA was positively related to $B C a$ cell proliferation. Furthermore, BORA knockdown induced cell cycle arrest in G2/M phase while BORA overexpression decreased the proportion of cells in G2/M, associated with PLK1-CDC25C-CDK1 alteration. Interestingly, we observed that knockdown of BORA inhibited BCa cell migration and invasion, accompanied with alterations of epithelial-mesenchymal transition (EMT) pathway related proteins. In vivo studies confirmed the inhibition effect of BORA knockdown on BCa cell growth and migration.
\end{abstract}

Conclusions: Our study indicates that BORA regulates BCa cell cycle and growth, meanwhile influences cell motility by EMT, and could be a novel biomarker and potential therapeutic target in BCa.

Keywords: Bladder cancer, BORA, Proliferation, Cell cycle, Epithelial-mesenchymal transition

\section{Background}

As the ninth most common cancer worldwide [1], bladder cancer $(\mathrm{BCa})$ is having a gradually increasing incidence in China [2]. Most of the newly diagnosed cases are non-muscle invasive $\mathrm{BCa}$. Even with transurethral resection of tumor, $\mathrm{BCa}$ still has a very high recurrence rate [3]. Chemotherapy based on cisplatin has improved the outcome modestly. For cisplatin-ineligible patients, T-cell checkpoint inhibitors have presented some benefits to

\footnotetext{
*Correspondence: wangxinghuan@whu.edu.cn

'Songtao Cheng and Tianchen Peng contributed equally to this work

1 Department of Urology, Zhongnan Hospital of Wuhan University, Wuhan, China

Full list of author information is available at the end of the article
}

those having high PD-L1 expression in some trials [4-6]. Except for the traditional chemotherapy drugs, there are no emerging new drugs for almost 30 years in $\mathrm{BCa}$ [7]. Therefore, to enhance the targeted and personalized therapy, molecular analysis to find more new specific markers and therapeutic targets is of great urgent.

$B O R A$ encoded protein activates kinase Aurora $\mathrm{A}$, and is very important in spindle assembly, centrosome maturation and the process of mitosis. BORA was identified as a cell cycle co-factor protein of Aurora A in the first place [8]. Binding with pole-like kinase 1 (PLK1), BORA forms a PLK1/BORA complex and recruits Aurora A to the T-loop of PLK1 T210 phosphorylation site to activate PLK1, thus promote mitotic entry [9]. PLK1 and Aurora A are critical regulators of cell cycle, which has

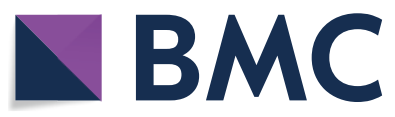

(c) The Author(s) 2020. This article is licensed under a Creative Commons Attribution 4.0 International License, which permits use, sharing, adaptation, distribution and reproduction in any medium or format, as long as you give appropriate credit to the original author(s) and the source, provide a link to the Creative Commons licence, and indicate if changes were made. The images or other third party material in this article are included in the article's Creative Commons licence, unless indicated otherwise in a credit line to the material. If material is not included in the article's Creative Commons licence and your intended use is not permitted by statutory regulation or exceeds the permitted use, you will need to obtain permission directly from the copyright holder. To view a copy of this licence, visit http://creativeco mmons.org/licenses/by/4.0/. The Creative Commons Public Domain Dedication waiver (http://creativecommons.org/publicdomain/ zero/1.0/) applies to the data made available in this article, unless otherwise stated in a credit line to the data. 
a fundamental role in cell proliferation, and related to the checkpoint recovery when DNA damage appears in cells where it leads to DNA repair or progress to apoptosis $[10,11]$. A variety of cell cycle related regulators have been explored as therapeutic targets and biomarkers [12]. PLK1 and Aurora A inhibitors have been extensively explored over the last few years and some of them showed prospective clinical benefits [13-16]. Moreover, compounds affecting the interaction of BORA and PLK1 may also have a good therapeutic potential [17]. Zhang et al. revealed that BORA was overexpressed in lung, breast, and gastric adenocarcinomas, and was an independent biomarker associated with poor prognosis [18]. Furthermore, recent studies reported that BORA was significantly related to radiosensitivity by influencing DNA repair and MDC1 [19]. Therefore, the genome stability and cell cycle regulated by Aurora A/BORA/PLK1 axis have a great important role in tumorigenesis and progress [20]. The roles of Aurora A and PLK1 have been extensively explored in a variety of cancers. However, the expression of BORA and its effects on tumor biology are rarely reported especially in $\mathrm{BCa}$.

Our group have screened a lot of differentially expressed genes through bioinformatics analysis of microarray data from $\mathrm{BCa}$ and normal bladder tissues $[21,22]$, and have verified several potential therapeutic targets and biomarkers associated with tumor progress and prognosis [23-26]. In the present study, we have verified that BORA was highly expressed in $\mathrm{BCa}$ compared to the normal bladder and paired paracancerous tissues, which was consistent with our microarray results. Further analysis indicated that BORA was positively associated with $\mathrm{BCa}$ cell proliferation. Knockdown of $B O R A$ induced cell cycle arrest in G2/M phase. Interestingly, we first found that reduced BORA repressed $\mathrm{BCa}$ cell mobility. Mouse model verified our in vitro results.

\section{Methods}

\section{Ethical statement of human tissues}

Bladder tissues were collected from the surgery of patients at Zhongnan Hospital of Wuhan University, and the normal tissues were from donors with accidental death. Tissues were obtained and stored following the protocol of Zhongnan Hospital Biobank. The study was conducted in accordance with the Declaration of Helsinki. Informed consent was obtained from all subjects and legally authorized representatives, and the approval of bladder tissues use was obtained from the Ethics Committee of Zhongnan Hospital (approval no. 2015029).

\section{Cell lines and culture}

Human bladder immortalized epithelium cell line SVHUC-1 (Cat. \#TCHu169), BCa cell lines RT-4 (Cat.
\#TCHu226), T24 (Cat. \#SCSP-536), UM-UC-3 (Cat. \#TCHu217) and 5637 (Cat. \#TCHu1) were got from Chinese Academy of Sciences, China. And BIU87 (Cat. \#CL-0035) was obtained from the Procell Co., Ltd., China. RT4 was maintained in McCoy's 5A medium (Gibco), UM-UC-3 was cultured in DMEM (Gibco), and all other cell lines were cultured in RPMI-1640 (Gibco). Fetal bovine serum (FBS, Gibco) was added to the culture medium to a final concentration of $10 \%$.

\section{Transfection and plasmid construction}

$\mathrm{BCa}$ cells were transfected with either siRNA or plasmid by Lipofectamine 2000 following the manufacture's protocol. The sense sequences of BORA-siRNA were: $S i-1$ (siBORA/shBORA), 5'-GGAGAUGUCAAGGAAUCA ATT-3'; Si-2, 5'-CCAGUAAAUGCACUAACAUTT-3'; $\mathrm{Si}-3,5^{\prime}$-GgAUAUGGUUGAUCCUAUATT-3'. The sicontrol (NC) was 5'-ACGUGACACGUUCGGAGA ATT-3'. The BORA overexpression plasmid pECMV3xFlag-BORA was obtained from GenePharma biotech company, China. To obtain stable BORA knockdown cell lines, UM-UC-3 and 5637 were infected with lentiviralcontrol-shRNA (LV-NC) and lentiviral-BORA-shRNA ( $L V-B O R A s h)$, and then selected with $5 \mu \mathrm{g} / \mathrm{ml}$ puromycin (Sigma).

\section{RNA extraction and qRT-PCR}

Total RNA was extracted from bladder tissues or cells using Qiagen RNeasy Mini Kit (Cat. \#74101) following the manufacture's protocol. The RNA quantity and quality were detected with NanoDrop ${ }^{\circledR}$ ND-2000 UV-Vis (Thermo Scientific). Then $1 \mu \mathrm{g}$ RNA was reverse transcribed to cDNA, which was then taken $1 \mu \mathrm{g}$ to mix with primers, $\mathrm{iQ}^{\mathrm{TM}} \mathrm{SYBR}^{\circledR}$-Green Supermix (Bio-Rad), and nuclease-free water to a final $20 \mu \mathrm{l}$ volume to amplify by real-time polymerase chain reaction. The forward primer of $B O R A$ is $5^{\prime}$-GAGAAAAGCGATGCTGCTTGT-3', and the reverse primer is $5^{\prime}$-GCTTCCGTTCCCATCTAA AAACA-3'. The forward primer of GAPDH is $5^{\prime}$-ACA ACTTTGGTATCGTGGAAGG- $3^{\prime}$, and the reverse primer is 5'-GCCATCACGCCACAGTTTC-3'.

\section{Cell proliferation and clonogenic formation assay}

After transfection with siRNA or plasmid for $48 \mathrm{~h}$, cells were transplanted into 96-well plates to proliferate for 1-5 days. As we described before, one plate was taken out every $24 \mathrm{~h}$ to treat with MTT and DMSO to detect the cell absorbance at $490 \mathrm{~nm}$ by microplate reader [22]. Clonogenic survival assay was performed with cells transfected after $48 \mathrm{~h}$ in 6 -well plates. Specifically, 800 UM-UC-3 cells/well and 1000 or 30005637 cells/ well were plated into 6 -well plates to form colonies for 
7-10 days. After that, colonies were fixed and stained to photograph and count for analysis.

\section{Flow cytometry analysis}

After transfection for $48 \mathrm{~h}$, cells were harvested in a $1.5 \mathrm{ml}$ centrifuge tube and then washed once with cold PBS. Resuspending cells in $1 \mathrm{ml} 1 \mathrm{X}$ DNA Staining solution and $10 \mu \mathrm{l}$ Permeabilization solution (Multi sciences, Cat. \#CCS012), vortexing for 5-10 s to mix well, and incubating $30 \mathrm{~min}$ at room temperature in a dark place. Then cells were tested on flow cytometry (Beckman, Cat. \#FC500) on cell cycle at the lowest loading speed. For apoptosis analysis, as we described before, apoptosis detection kit (BD biosciences, Cat. \#558547) was used according to its instruction [22].

\section{Transwell chamber assay}

Cells transfected after $48 \mathrm{~h}$ were transplanted into the upper transwell chamber (Corning) with (4-6) $\times 10^{4}$ cells resuspended in $200 \mu \mathrm{l}$ culture medium with no FBS. And the lower chamber added in $600 \mu \mathrm{l}$ culture medium with $10 \% \mathrm{FBS}$ to induce cell invasion and migration. Incubating for $24 \mathrm{~h}$ in cell incubator, cells in the upper chamber were removed. The go-through cells on the bottom side of the upper chamber were fixed and stained to photograph and count under the phase contrast microscope. The different step for invasion assay was that the transwell chamber was percolated with ECM Matrix gel (Sigma-Aldrich) before the cell seeding.

\section{Protein extraction and western blot (WB) analysis}

RIPA with protease inhibitor and phosphatase inhibitor (Sigma-Aldrich) was used to lyse BCa cells. After $30 \mathrm{~min}$ on ice, cells were centrifuged at $4{ }^{\circ} \mathrm{C}$ and the supernatant was the protein solution. After a bath in boiling water for $10 \mathrm{~min}$, the protein solution was ready to test. Protein was separated in SDS-PAGE gels, then transferred to PVDF membrane (Millipore), blocked with 5\% milk, and incubated with primary (Additional file 1: Table S1) and secondary antibodies (Additional file 1: Table S2) sequentially. Bands were developed with chemiluminescence kit (Bio-Rad) and detected by Bio-Rad $\mathrm{XRS}^{+}$Imaging system.

\section{Immunofluorescence (IF), immunohistochemistry (IHC),} and hematoxylin and eosin (H\&E) staining

Immunofluorescence staining for cells was described before [25]. For bladder tissues, immunofluorescence was performed by Biofavor Biotech, China. For IHC, paraffin section was sequentially going through deparaffinage, antigen retrieval, endogenous peroxidase inactivating, blocking with goat serum (Gibco), and incubating with primary (Additional file 1: Table S1) and secondary
(Additional file 1: Table S2) antibodies. For H\&E staining, the paraffin section of mice lung tissues and xenograft tumors were sequentially deparaffinized, rehydrated, stained with hematoxylin and eosin (Sigma-Aldrich), dehydrated and sealed. The slices were visualized and photographed with phase contrast microscope (Leica, Cat. \#DMI 1).

\section{Xenograft and pulmonary metastasis mouse model}

The 3-week-old male BALB/c-nu mice were purchased from Beijing HFK Bioscience Co., Ltd., China, and adapted 1 week to the animal facility of Zhongnan Hospital of Wuhan University. $4 \times 10^{6} 5637 L V-N C$ or $L V$-BORA sh cells in $150 \mu \mathrm{l}$ PBS were subcutaneously injected into the right flank to establish the xenograft model $(n=4)$. Xenograft tumor size was measured every 3 days (tumor volume $=$ length $\times$ width $^{2} \times 0.5$ ). And after 32 days of injection, tumor tissues were isolated from sacrificed mice to weigh and fixed in PFA for subsequent experiments. $1 \times 10^{6} \mathrm{UM}-\mathrm{UC}-3 \mathrm{LV}$-NC or $L V$-BORA sh cells in $100 \mu \mathrm{l}$ PBS were intravenously injected into tail vein to establish the pulmonary metastasis model $(n=3)$. Six weeks after injection, the fluorescence of pulmonary metastasis was monitored with FUSION FX7 Spectra Imaging system (Vilber), and the lung tissues were isolated to fix in 4\% PFA for H\&E staining. The animal experiment was in accordance with animal welfare and European animal care guidelines, and approved by the Institutional Animal Care and Use Committee at Center for Animal Experiment, Wuhan University (approval no. 2018152).

\section{Statistics}

Representative data were from at least three independent iterations. Statistical analyses were carried out with SPSS 16.0. Two-tailed Student's t-test and one-way analysis of variance were used to evaluate whether the difference of data was statistically significant, and $\mathrm{p}<0.05$ was considered significant.

\section{Results \\ Upregulated BORA in BCa tissues}

We searched Oncomine database to find that mRNA expression of $B O R A$ was significantly increased in $\mathrm{BCa}$ compared to normal bladder (Fig. 1a). Gene Expression Profiling Interactive Analysis (GEPIA) is a website to easily achieve data visualization based on TCGA and GTEx projects [27]. The results showed that BORA was highly expressed in 404 tumor tissues compared to 28 normal tissues in bladder (Fig. 1b). To strengthen the results, we verified the mRNA and protein expression of BORA in $\mathrm{BCa}$ and paracancerous tissues collected from our hospital. qRT-PCR results revealed that BORA was 

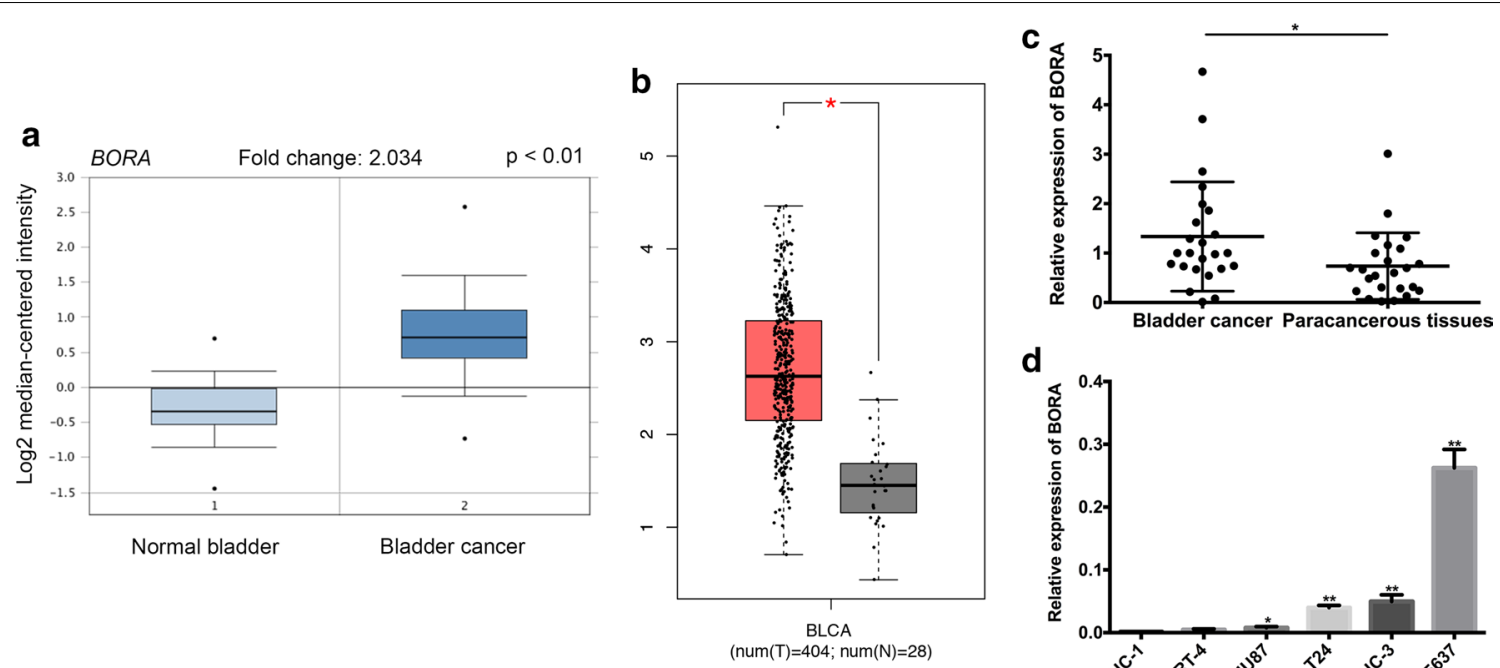

e
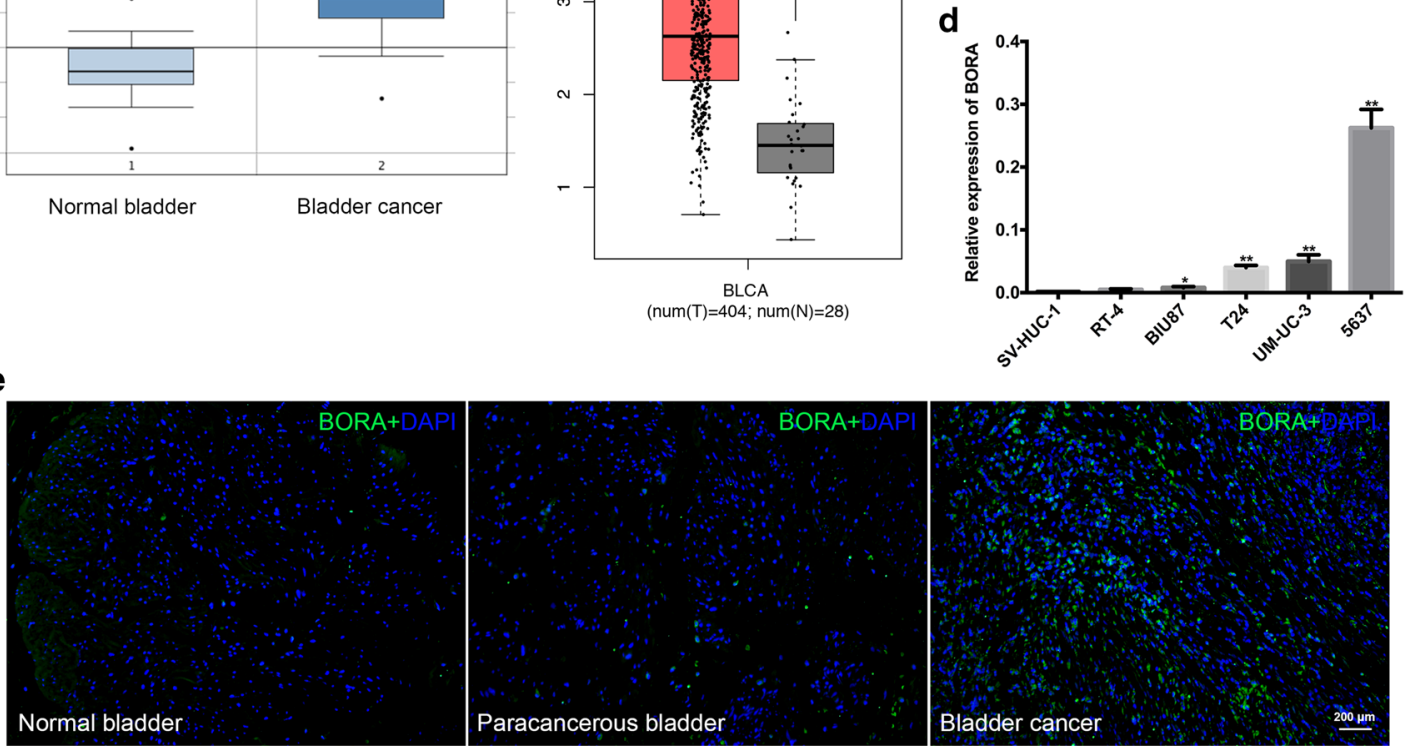

al bladder

Fig. 1 BORA was upregulated in BCa tissues. Upregulation of BORA was verified in Oncomine database (a) and GEPIA (b). c qRT-PCR results from our tissues indicated that BORA expression was significantly increased in BCa compared to matched paracancerous tissues. $\mathbf{d} B O R A$ expression in human immortalized normal bladder epithelium cell and BCa cell lines. GAPDH was the reference gene. ${ }^{*} p<0.05,{ }^{* *} p<0.01$. e Representative IF staining of BORA (green) in normal bladder, paracancerous bladder and BCa tissues, with DAPI (blue) stained nuclei. The scale bar is indicated

upregulated in $\mathrm{BCa}$ tissues $(\mathrm{n}=24)$ in comparison with paired paracancerous tissues (Fig. 1c). Furthermore, IF staining verified the upregulation of BORA in $\mathrm{BCa}$ tissues compared to paracancerous and normal tissues (Fig. 1e). All the results were consistent with our previous microarray results of 3 pairs of human $\mathrm{BCa}$ and normal bladder tissues [21]. We then detected the mRNA expression of BORA in $\mathrm{BCa}$ cell lines in comparison with human immortalized normal bladder epithelium cell line SV-HUC-1. Upregulated BORA was found in BCa cell lines, and among which, 5637 and UM-UC-3 were the most (Fig. 1d). Therefore, we chose 5637 and UM-UC-3 cell lines for the following experiments.

\section{Positive regulation of BORA in $\mathrm{BCa}$ cell proliferation}

To establish BORA knockdown cell model, UM-UC-3 and 5637 cells were transfected with three BORA-target-siRNAs. The knockdown efficiency was confirmed by qRT-PCR (Additional file 1: Figure S1A, B). We then chose the most efficient $S i-1$ from the three siRNAs as the representative $\operatorname{SiBOR} A$ to knockdown $B O R A$ in $\mathrm{BCa}$
UM-UC-3 and 5637 cells, which was confirmed by WB (Additional file 1: Figure S1C) and IF assay (Fig. 2a). After knockdown of $B O R A$, cell proliferation was significantly suppressed in UM-UC-3 (Fig. 2b) and 5637 (Fig. 2c) compared to the control NC group. Moreover, clonogenic formation results showed that BORA knockdown reduced the cell ability of colony formation (Fig. 2d), confirmed by statistical analysis (Fig. 2e). IF staining of the important proliferation marker Ki-67 [28], also revealed that BORA knockdown reduced Ki-67 positive cells (Fig. 2f). Furthermore, we constructed a BORA overexpression plasmid to figure out what was the effects of overexpressed BORA in BCa cells. Overexpression cell model was established by transfection of BORA plasmid into UM-UC-3 and 5637 cells, which was verified by qRT-PCR (Additional file 1: Figure S1D) and WB assays (Additional file 1: Figure S1E). Our results suggested that BORA overexpression had a proliferation-promoting effect in UM-UC-3 (Fig. 2g) and 5637 cells (Fig. 2h) compared to the control EV group and increased $\mathrm{BCa}$ cell clonogenic formation efficiency (Fig. 2i, j). 

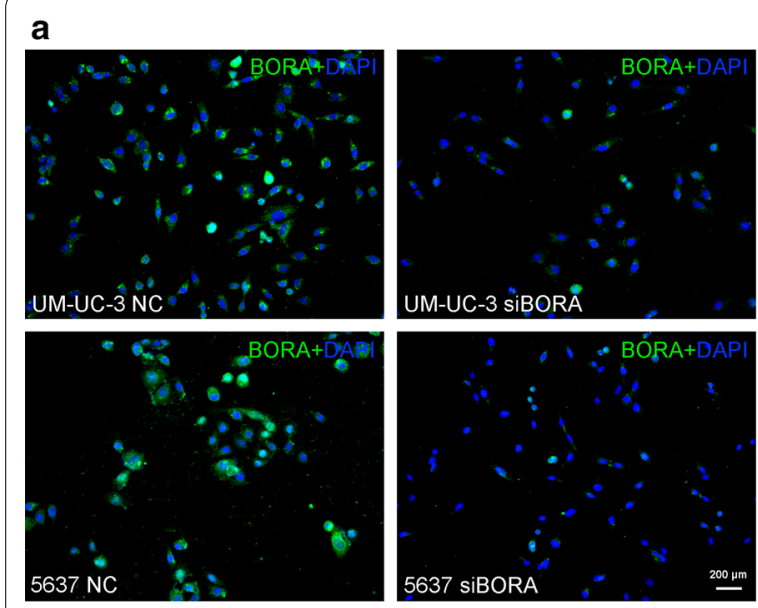

f
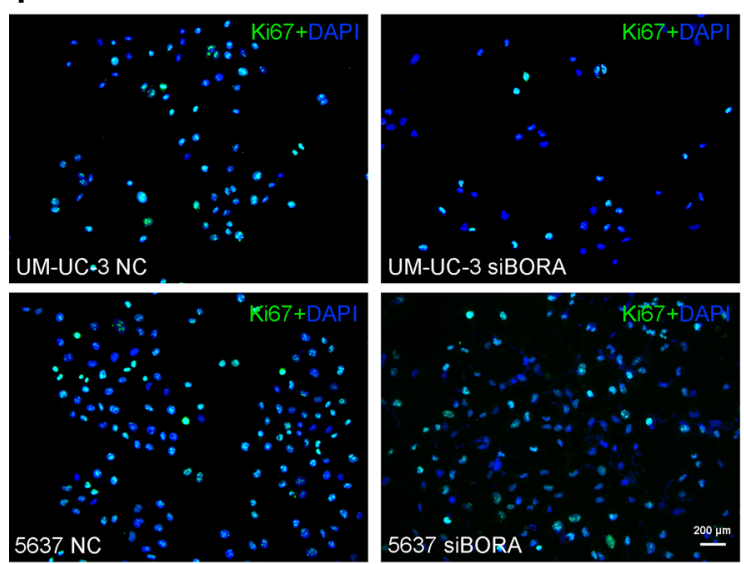

b
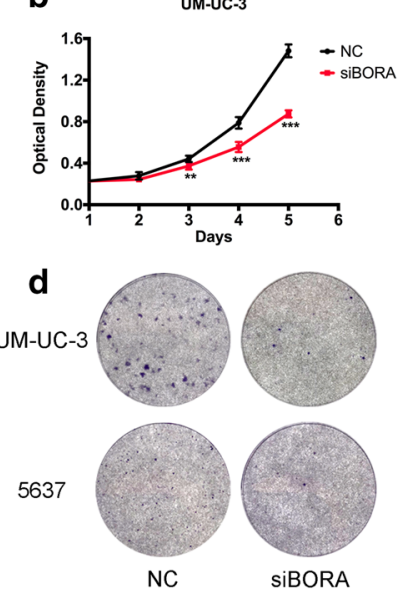

g
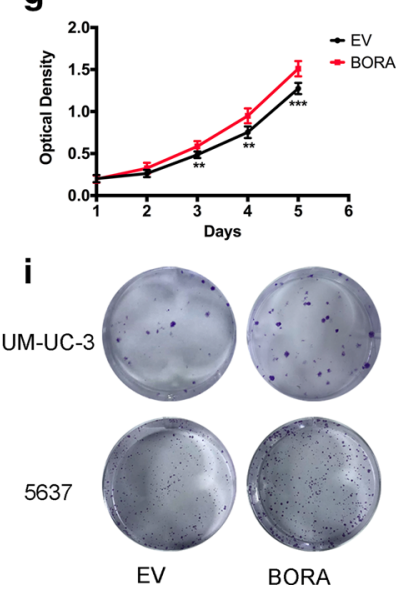

C

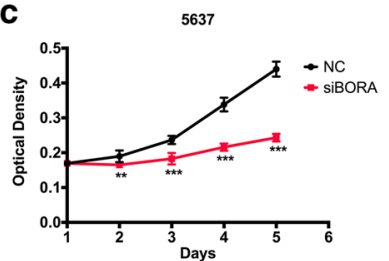

e

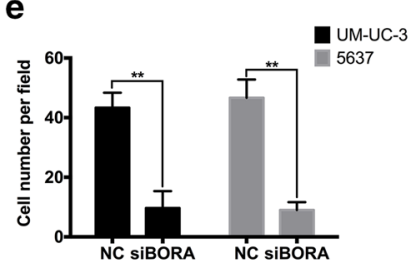

h

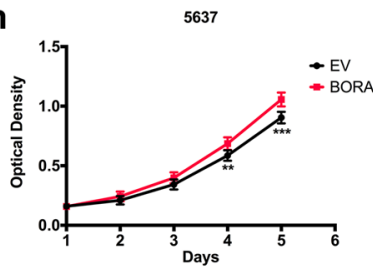

j

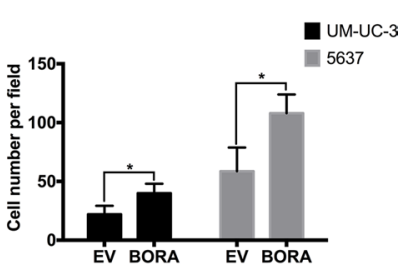

Fig. 2 Influence of BORA on BCa cell proliferation. a IF staining confirmed the knockdown of BORA. The scale bar is indicated. $\mathbf{b}$ MTT assay to test the viability of UM-UC-3 and $\mathbf{c} 5637$ cells transfected with siBORA or NC. $\mathbf{d}$ Influence of BORA knockdown on clonogenic formation efficiency and $\mathbf{e}$ statistical analysis of three independent experiments. $\mathbf{f} \mid \mathrm{F}$ staining of Ki-67. The scale bar is indicated. $\mathbf{g}$ MTT assay to test the influence of overexpressed BORA on cell proliferation in BCa UM-UC-3 and $\mathbf{h} 5637$ cells. And $\mathbf{i}$ the clonogenic formation assay (j) with statistical results. ${ }^{*} p<0.05$, ${ }^{* *} p<0.01,{ }^{* * *} p<0.001$

\section{Knockdown of BORA induced cell cycle arrest in G2/M phase}

Cancer proliferation is related to an active mitosis [29]. Then, flow cytometry was taken to assess the cell cycle conditions after transfection. Our results revealed that knockdown of $B O R A$ in UM-UC-3 and 5637 cells induced cell cycle arrest in $\mathrm{G} 2 / \mathrm{M}$ phase (Fig. 3a), as indicated by statistical analysis (Fig. 3b). We also observed cell cycle related kinases CDK1 and CDK2 had a significant downregulation after $B O R A$ knockdown, while CCNA and CCNB1 protein had an upregulation as showed in Fig. 3c. PLK1/CDC25 was reported to have an important role in regulating the activation of CDK1 [30]. Also, p21 was a critical upstream regulator of cell cycle [31]. Their protein expression showed an obvious increase after $B O R A$ knockdown in UM-UC-3 and 5637 cells (Fig. 3c). We then detected the changes of apoptosis rate and found that BORA inhibition only was not enough to promote apoptosis in BCa UM-UC-3 and 5637 cells (Additional file 1: Figure S1F), which indicated a more complex regulation of apoptosis in cells. Furthermore, overexpression of BORA significantly reduced the proportion of G2/M phase in cell cycle (Fig. 3d), confirmed by statistical analysis (Fig. 3e). Also, the expression of cell cycle related protein $C D K 1$ and $C D K 2$ were upregulated, while CCNB1, CCNA, p21, PLK1, and CDC25C had a downregulation (Fig. 3f). 


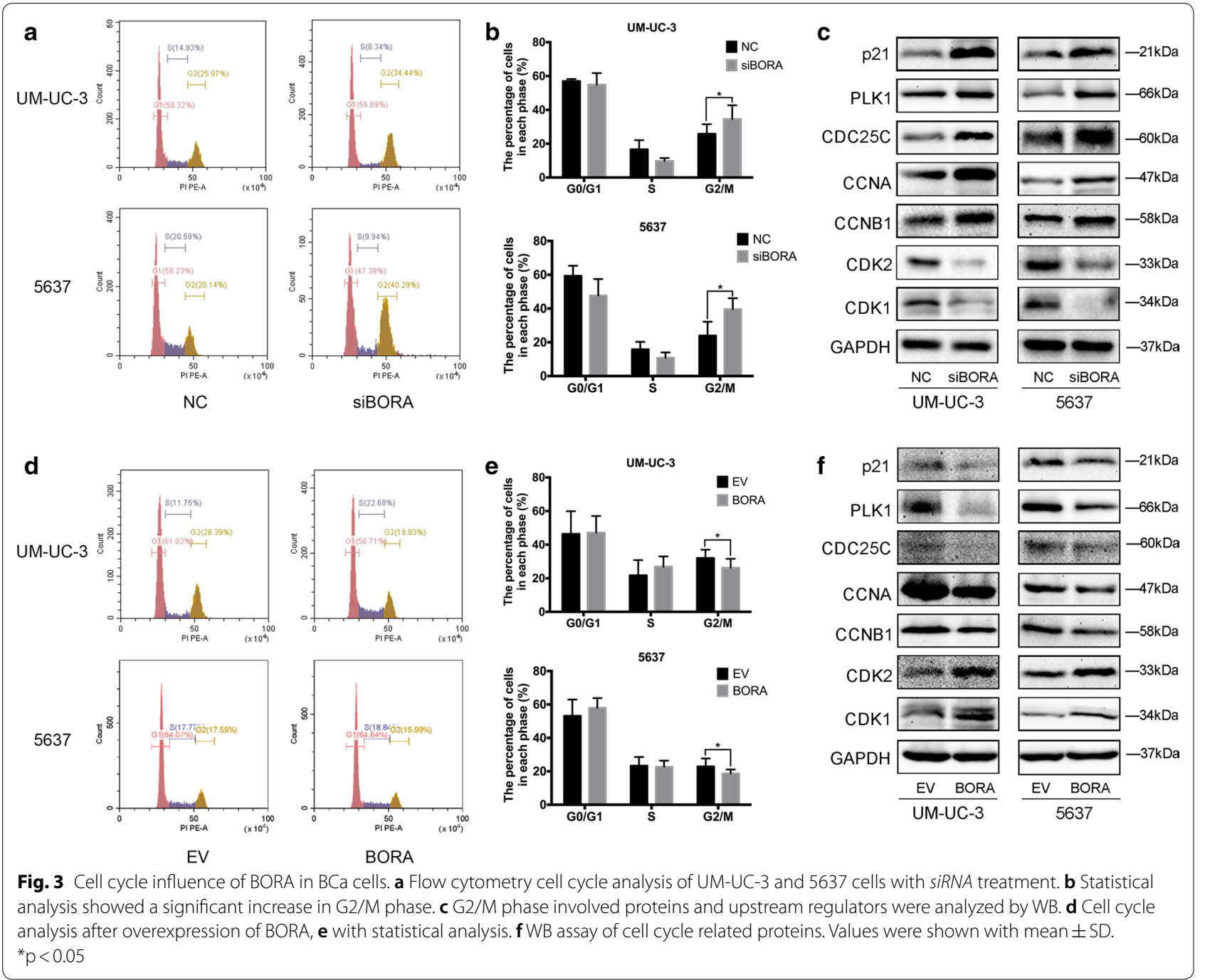

\section{BORA affected BCa cell motility with EMT-related proteins alteration}

Interestingly, after knockdown of $B O R A$, we noticed a reduction of transwell migration (Fig. 4a) and invasion rate (Fig. 4b) in UM-UC-3 and 5637 cells compared to NC group. Statistical analysis of the results from 3 independent experiments confirmed the significance of difference of migration (Fig. 4c) and invasion (Fig. 4d) rate reduction. The change of migration and invasion capacity in cancer usually associated with EMT process [32]. Therefore, we detected the EMT-related proteins and observed that the most important epithelial marker E-cadherin was upregulated, while mesenchymal and other EMT-related markers such as N-cadherin, Vimentin, MMP2, MMP9, and $\beta$-catenin were downregulated in BORA knockdown cells (Fig. 4e).

\section{BORA knockdown inhibited BCa cell proliferation}

\section{and pulmonary metastasis in vivo}

We conducted lentiviral packaging of BORA shRNA to establish stably downregulated $\mathrm{BCa}$ cells to verify the effect of BORA on cell growth and metastasis in vivo. The knockdown efficiency was confirmed by qRT-PCR in UM-UC-3 (Fig. 5a) and 5637 cells (Fig. 5b) before injection. In the xenograft mice transplanted with 5637 , $L V$-BORA sh group showed a suppressed tumor growth compared to $L V-N C$ group (Fig. $5 \mathrm{c}$ ). Tumor tissues were isolated from mice after sacrificing to weigh, and the tumor weight of $L V-B O R A$ sh group was significantly lower than that of $L V-N C$ group (Fig. $5 \mathrm{~d}$ ). Tumor tissues were then paraffin-embedded and stained with H\&E (Fig. 5e). Moreover, IHC staining confirmed that BORA expression of the tumor in $L V-B O R A$ sh group 

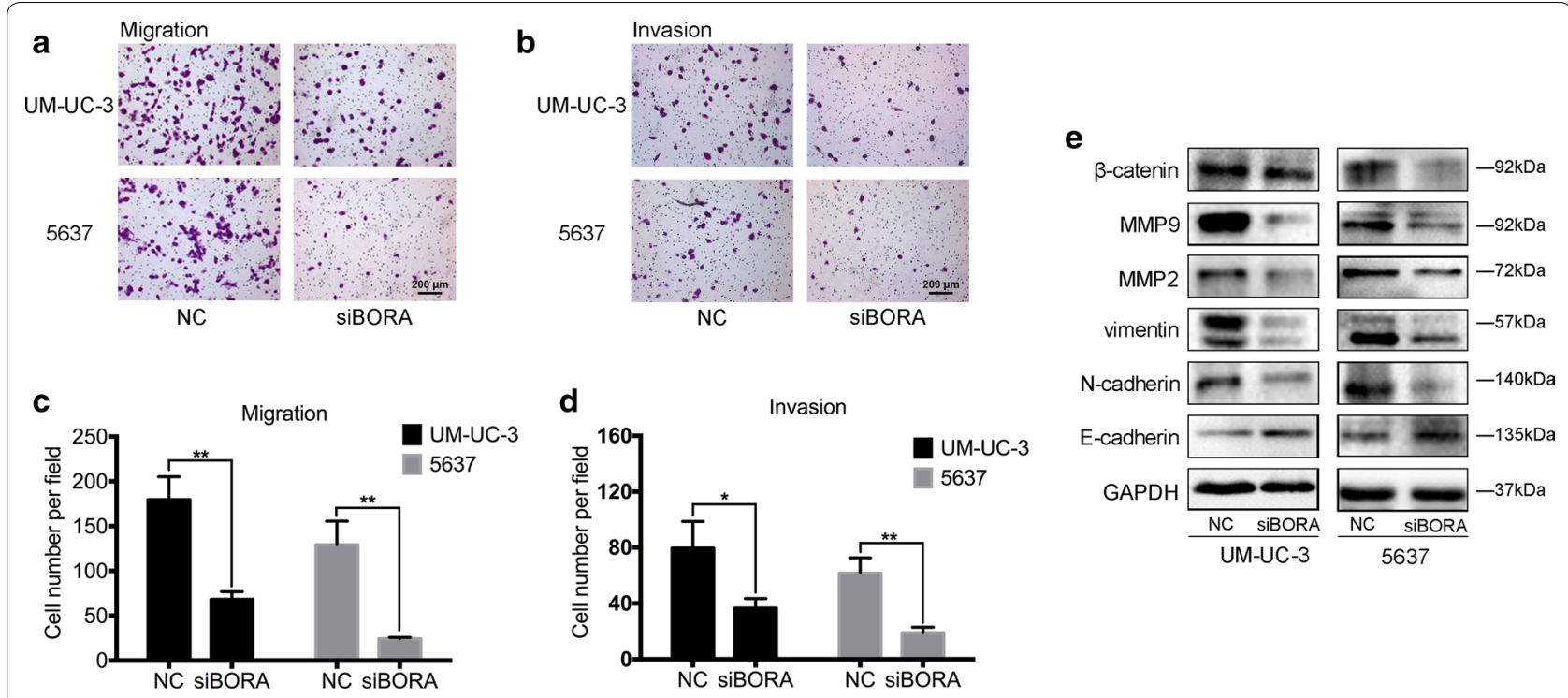

Fig. 4 BORA regulated BCa cell migration and invasion via EMT. a Transwell migration and b invasion assays of UM-UC-3 and 5637 cells. c Statistical analysis showed a significant decrease of migration and $\mathbf{d}$ invasion rate of cells transfected with siBORA. e WB results showed the alteration of proteins related to EMT pathway. ${ }^{*} p<0.05,{ }^{* *} p<0.01$

was downregulated, and the proliferation marker Ki-67 also showed a decreased expression in $L V$-BORA sh group compared to $L V$-NC group (Fig. 5e). For pulmonary metastasis, $L V$-BORA sh UM-UC-3 and $L V-N C$ UM-UC-3 cells were tail intravenously injected. Six weeks after injection, the fluorescence of pulmonary metastasis was detected, and the results suggested that knockdown of BORA significantly reduced $\mathrm{BCa}$ cell migration in vivo compared to $L V$-NC group (Fig. $5 \mathrm{f}$ ).

\section{Discussion}

As the activator of kinase Aurora A, BORA plays an important role in asymmetric protein localization, spindle assembly, and centrosome maturation during mitosis [8]. Most of the studies were focused on Aurora A and the interaction of BORA between Aurora A and PLK1 [20]. The function of BORA in cancer was seldomly researched especially in bladder cancer. Our previous microarray analysis of $\mathrm{BCa}$ and normal bladder tissues, which could be downloaded at Gene Expression Omnibus database with accession number GSE76211, showed upregulation of BORA expression in BCa tissues [21]. Therefore, in the present study, we firstly confirmed that the expression of BORA was upregulated in $\mathrm{BCa}$ tissues in comparison with normal bladder and paired paracancerous bladder tissues from our center combining with TCGA and Oncomine database (Fig. 1).

To explore the function of BORA in $\mathrm{BCa}$, we established BORA knockdown and overexpression $\mathrm{BCa}$ cell model. Our results showed that knockdown of BORA could inhibit BCa cell proliferation and BORA overexpression could promote cell proliferation (Fig. 2). Cell growth is regulated by cell cycle activity, and BORA was reported to strengthen the activation of PLK1 to facilitate G2/M transition [33]. In our study, reduced BORA induced cell cycle arrest in G2/M phase, and upregulation of BORA decreased cells in G2/M (Fig. 3). G2/M entry is controlled by Cyclin-dependent kinase CDK1CCNB and CDK1-CCNA. The activity of CDK1 is regulated by PLK1 through promoting CDC25 activation [30]. The activation of PLK1 relies on the phosphorylation of T210 residue at its T-loop [34], which is the result of Aurora A kinase effect with the cooperation of BORA [35]. However, some studies also showed that PLK1 and Aurora A conversely had an influence on BORA activity through posttranslational modifications $[8,36]$. Recent studies demonstrated that CDK1 regulated the activation of BORA by phosphorylating 3 conserved sites located at the $\mathrm{N}$-terminal part of BORA, which are Cyclin docking sites [20,37]. Once mutated the three phosphorylation sites of BORA, PLK1 could not be activated by Aurora $\mathrm{A}$ at T210 on the T-loop. During DNA damage recovery, it is important for cells to maintain the G2 checkpoint, which provides cells with time for DNA repair or progress to apoptosis. Cairns et al. reported that BORA was significantly related to radiosensitivity by regulating DNA repair and MDC1, and BORA affected irradiation response via a different pathway from PLK1 [19]. We detected the expression of cell cycle proteins and found that PLK1 and CDC25C were upregulated, while 


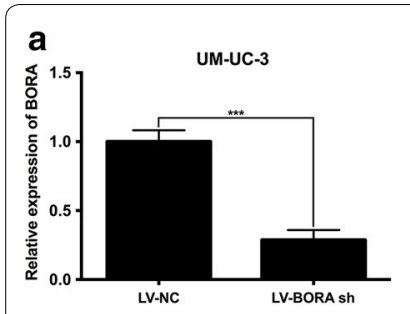

e

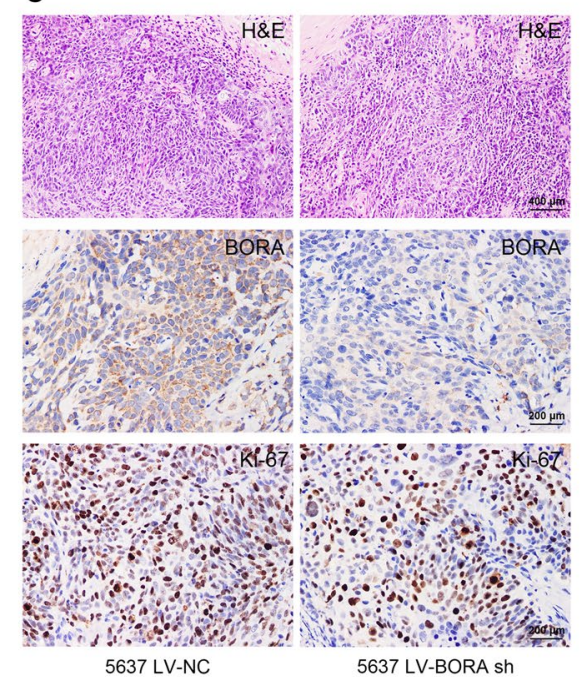

5637 LV-NC

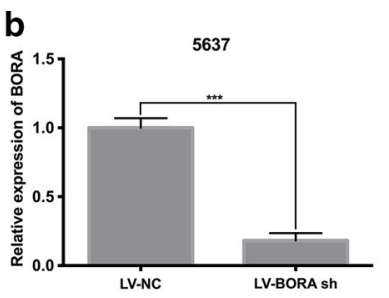

f
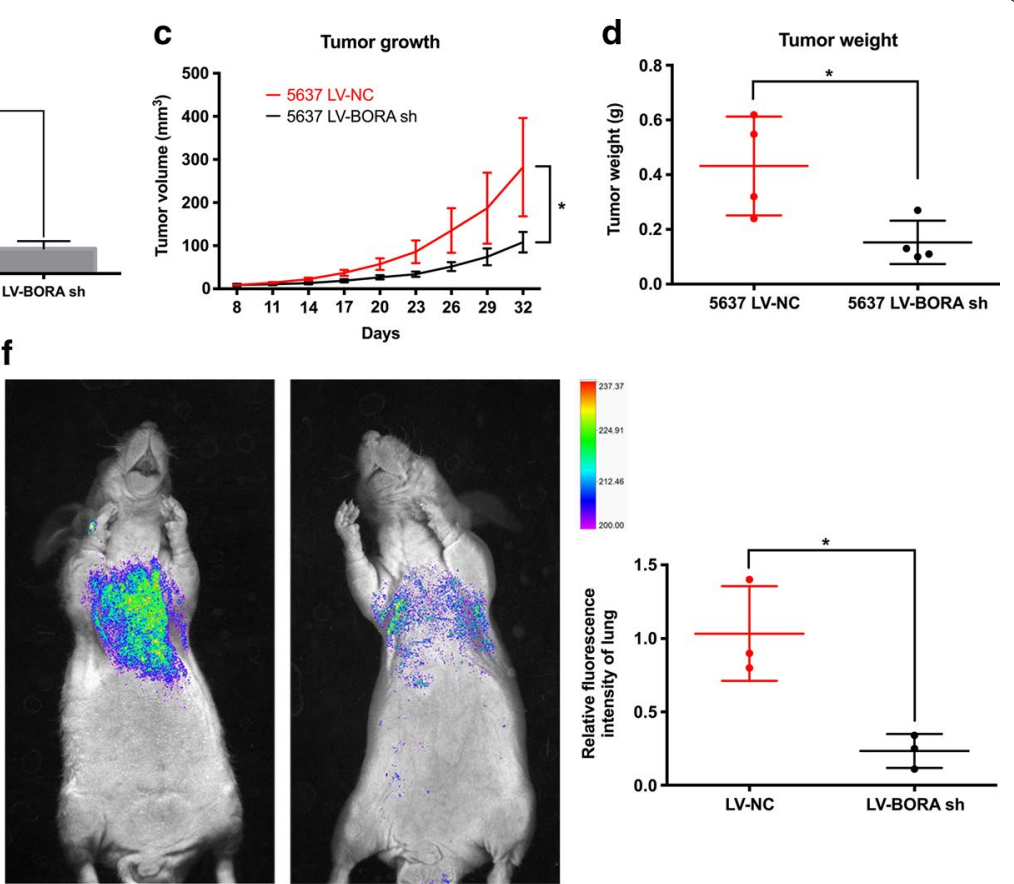
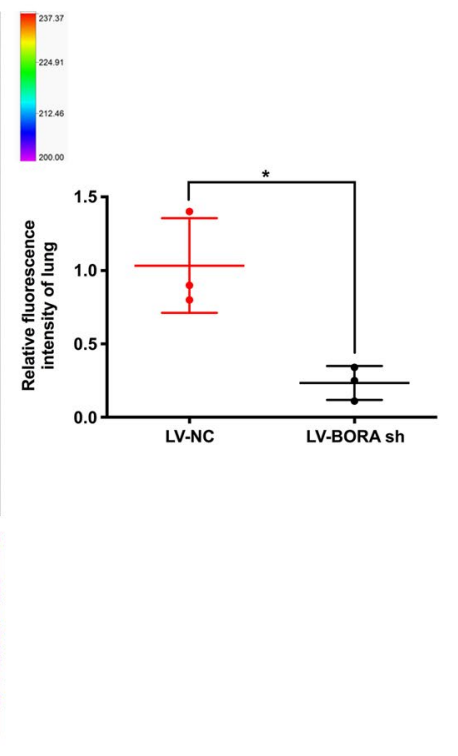

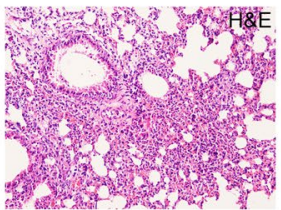

UM-UC-3 LV-NC

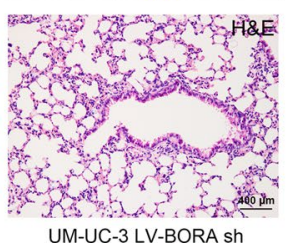

Fig. 5 BORA knockdown inhibited $B C$ a growth and migration in vivo. a Stable cell lines of BORA knockdown were established and confirmed by qPCR in UM-UC-3 and $\mathbf{b} 5637$ cells. c Tumor volume was measured every 3 days. The $x$-axis represents days after transplantation. $\mathbf{d}$ The weight of the isolated tumor tissues. e Representative H\&E and IHC staining of tumor tissues. The scale bar was indicated. $\mathbf{f}$ Fluorescence of pulmonary metastasis and statistics, and representative H\&E staining of lung tissues. The scale bar was indicated. ${ }^{*} p<0.05$

CDK1 and CDK2 were downregulated after knockdown of $B O R A$. Moreover, the protein changes were reversed after BORA overexpression in BCa cells (Fig. 3). GSK3 $\beta$ activation was reported to be important for BORA [38]. We noticed a downregulation of GSK3 $\beta$ after BORA knockdown in UM-UC-3 cells (data not shown). However, the exact mechanism of how BORA regulates and be regulated in the feedback loops still needs to be further explored.

Interestingly, after knockdown of $B O R A$, we noticed that $\mathrm{BCa}$ cell migration and invasion were inhibited, which has not been reported anywhere else (Fig. 4). We observed upregulated epithelial marker E-cadherin in $B O R A$ knockdown cells and downregulated $\mathrm{N}$-cadherin, Vimentin and other proteins associated with EMT pathway, which has been verified to play a critical role in migration and invasion of cancer cells [39]. But how reduced BORA exactly regulates EMT still needs further detections. To confirm our in vitro results, we established stable cell lines of BORA knockdown through lentiviral packaging. Xenografts and pulmonary metastasis mice model were established by subcutaneously and intravenously injecting $\mathrm{BCa}$ cells, respectively. In vivo, we also found reduced $\mathrm{BCa}$ cell growth and migration after knockdown of BORA (Fig. 5).

Recently, a large number of Aurora A and PLK1 inhibitors were reported to be evaluated in clinical trials as anticancer drugs but showed modest effect against solid tumors [40]. BORA, as the key intermediate protein of Aurora A and PLK1, was reported to be a potential biomarker for prognosis in lung, breast, and gastric adenocarcinomas [18]. Our results also showed that BORA knockdown could suppress $\mathrm{BCa}$ cell growth and migration both in vitro and in vivo. Researches about the effect of BORA in cancers are still too less. And how PLK1 and Aurora A inhibitors affect solid tumors after blockading BORA needs to be further investigated. As a signaling node of the BORA-PLK1-CDC25-CDK1 feedback loop and Aurora A-BORA-PLK1 axis, BORA is likely to have exciting prospects as a potential target. 


\section{Conclusions}

In conclusion, our study revealed that BORA positively associated with $\mathrm{BCa}$ cell growth and regulated cell cycle. For the first time, we found that BORA knockdown could suppress $\mathrm{BCa}$ cell migration and invasion possibly through EMT pathway. BORA has the potential to become a new biomarker and possible therapeutic target in $\mathrm{BCa}$.

\section{Supplementary information}

Supplementary information accompanies this paper at https://doi. org/10.1186/s12935-020-01392-8.

\section{Additional file 1: Figure S1. Validation of BORA knockdown and} overexpression. Knockdown efficiency of BORA-siRNA in (A) UM-UC-3 and (B) 5637 cells. (C) WB confirmed the knockdown of BORA. (D) BORA overexpression was verified by $q P C R$ and (E) WB assay. (F) Apoptosis analysis of BORA knockdown. ${ }^{* *} p<0.01,{ }^{* *} p<0.001$, n.s. means no significance. Table S1. List of primary antibodies. Table S2. List of secondary antibodies.

\section{Abbreviations}

BCa: Bladder cancer; EMT: Epithelial-mesenchymal transition; GEPIA: Gene Expression Profiling Interactive Analysis; H\&E: Hematoxylin and eosin; IF: Immunofluorescence; IHC: Immunohistochemistry; PLK1: Pole-like kinase 1; WB: Western blot.

\section{Acknowledgements}

We appreciate the great help of technical assistance from Ms. Yuan Zhu, Ms. Yayun Fang and Ms. Danni Shan.

\section{Authors' contributions}

SC, TP and LJ designed and conducted the experiment. SC, XZ, FZ and GW collected data and analyzed. $L J, S C, X L, Y X$ and XW wrote and revised the manuscript. All authors read and approved the final manuscript.

\section{Funding}

We are grateful for the tremendous support from China Scholarship Council.

\section{Availability of data and materials}

All data generated or analysed during this study are included in this published article.

\section{Ethics approval and consent to participate}

Bladder tissues were collected from the surgery of patients at Zhongnan Hospital of Wuhan University, and the normal tissues were from donors with accidental death. Tissues were obtained and stored following the protocol of Zhongnan Hospital Biobank. The study was conducted in accordance with the Declaration of Helsinki. Informed consent was obtained from all subjects and legally authorized representatives, and the approval of bladder tissues use was obtained from the Ethics Committee of Zhongnan Hospital (approval no. 2015029).

\section{Consent for publication}

Not applicable.

\section{Competing interests}

The authors declare that they have no competing interests.

\section{Author details}

1 Department of Urology, Zhongnan Hospital of Wuhan University, Wuhan, China. ${ }^{2}$ Department of Pathology, Lombardi Comprehensive Cancer Center, Georgetown University Medical School, Washington, DC, USA. ${ }^{3}$ Cancer Precision Diagnosis and Treatment and Translational Medicine Hubei Engineering Research Center, Wuhan, China. ${ }^{4}$ Department of Ophthalmology, Zhongnan
Hospital of Wuhan University, Wuhan, China. ${ }^{5}$ Department of Biological Repositories, Zhongnan Hospital of Wuhan University, Wuhan, China. ${ }^{6}$ Human Genetics Resource Preservation Center of Wuhan University, Wuhan, China. ${ }^{7}$ Human Genetics Resource Preservation Center of Hubei Province, Wuhan, China.

Received: 27 April 2020 Accepted: 30 June 2020

Published online: 06 July 2020

References

1. Antoni S, Ferlay J, Soerjomataram I, Znaor A, Jemal A, Bray F. Bladder cancer incidence and mortality: a global overview and recent trends. Eur Urol. 2017;71(1):96-108

2. Chen W, Zheng R, Baade PD, Zhang S, Zeng H, Bray F, Jemal A, Yu XQ, He J, Cancer statistics in China, 2015. CA Cancer J Clin. 2016;66(2):115-32.

3. Prasad SM, Decastro GJ, Steinberg GD. Medscape: urothelial carcinoma of the bladder: definition, treatment and future efforts. Nat Rev Urol. 2011;8(11):631-42.

4. Balar AV, Galsky MD, Rosenberg JE, Powles T, Petrylak DP, Bellmunt J, Loriot Y, Necchi A, Hoffman-Censits J, Perez-Gracia JL, et al. Atezolizumab as first-line treatment in cisplatin-ineligible patients with locally advanced and metastatic urothelial carcinoma: a single-arm, multicentre, phase 2 trial. Lancet. 2017;389(10064):67-76.

5. Bellmunt J, de Wit R, Vaughn DJ, Fradet $Y$, Lee JL, Fong L, Vogelzang NJ, Climent MA, Petrylak DP, Choueiri TK, et al. Pembrolizumab as second-line therapy for advanced urothelial carcinoma. N Engl J Med. 2017:376(11):1015-26.

6. Sonpavde G. PD-1 and PD-L1 inhibitors as salvage therapy for urothelial carcinoma. N Engl J Med. 2017;376(11):1073-4.

7. Zhang Z, Zhang G, Kong C. Targeted inhibition of Polo-like kinase 1 by a novel small-molecule inhibitor induces mitotic catastrophe and apoptosis in human bladder cancer cells. J Cell Mol Med. 2017;21(4):758-67.

8. Hutterer A, Berdnik D, Wirtz-Peitz F, Zigman M, Schleiffer A, Knoblich JA. Mitotic activation of the kinase Aurora-A requires its binding partner Bora. Dev Cell. 2006;11(2):147-57.

9. Bruinsma W, Aprelia M, Garcia-Santisteban I, Kool J, Xu YJ, Medema RH. Inhibition of Polo-like kinase 1 during the DNA damage response is mediated through loss of Aurora A recruitment by Bora. Oncogene. 2017;36(13):1840-8.

10. van Vugt MA, Bras A, Medema RH. Polo-like kinase-1 controls recovery from a G2 DNA damage-induced arrest in mammalian cells. Mol Cell. 2004;15(5):799-811.

11. Hanahan D, Weinberg RA. Hallmarks of cancer: the next generation. Cell. 2011;144(5):646-74

12. Ju LG, Zhu Y, Long QY, Li XJ, Lin X, Tang SB, Yin L, Xiao Y, Wang XH, Li L, et al. SPOP suppresses prostate cancer through regulation of CYCLIN E1 stability. Cell Death Differ. 2019;26(6):1156-68.

13. Zhou N, Singh K, Mir MC, Parker Y, Lindner D, Dreicer R, Ecsedy JA, Zhang Z, Teh BT, Almasan A, et al. The investigational Aurora kinase A inhibitor MLN8237 induces defects in cell viability and cell-cycle progression in malignant bladder cancer cells in vitro and in vivo. Clin Cancer Res. 2013;19(7):1717-28.

14. Gjertsen BT, Schoffski P. Discovery and development of the Polo-like kinase inhibitor volasertib in cancer therapy. Leukemia. 2015;29(1):11-9.

15. Graff JN, Higano CS, Hahn NM, Taylor MH, Zhang B, Zhou X, Venkatakrishnan K, Leonard EJ, Sarantopoulos J. Open-label, multicenter, phase 1 study of alisertib (MLN8237), an aurora A kinase inhibitor, with docetaxel in patients with solid tumors. Cancer. 2016;122(16):2524-33.

16. Pujade-Lauraine E, Selle F, Weber B, Ray-Coquard IL, Vergote I, Sufliarsky J, Del Campo JM, Lortholary A, Lesoin A, Follana P, et al. Volasertib Versus chemotherapy in platinum-resistant or -refractory ovarian cancer: a randomized phase II Groupe des Investigateurs Nationaux pour l'Etude des Cancers de l'Ovaire Study. J Clin Oncol. 2016;34(7):706-13.

17. Cirillo L, Thomas Y, Pintard L, Gotta M. BORA-dependent PLK1 regulation: a new weapon for cancer therapy? Mol Cell Oncol. 2016;3(5):e1 199265.

18. Zhang QX, Gao R, Xiang J, Yuan ZY, Qian YM, Yan M, Wang ZF, Liu Q, Zhao HD, Liu CH. Cell cycle protein Bora serves as a novel poor prognostic factor in multiple adenocarcinomas. Oncotarget. 2017:8(27):43838-52. 
19. Cairns J, Peng Y, Yee VC, Lou Z, Wang L. Bora downregulation results in radioresistance by promoting repair of double strand breaks. PLOS ONE. 2015;10(3):e0119208.

20. Parrilla A, Cirillo L, Thomas Y, Gotta M, Pintard L, Santamaria A. Mitotic entry: the interplay between Cdk1, PIk1 and Bora. Cell Cycle. 2016;15(23):3177-82.

21. Wang G, Cao R, Wang Y, Qian G, Dan HC, Jiang W, Ju L, Wu M, Xiao Y, Wang $X$. Simvastatin induces cell cycle arrest and inhibits proliferation of bladder cancer cells via PPARgamma signalling pathway. Sci Rep. 2016;6:35783.

22. Cheng S, Wang G, Wang Y, Cai L, Qian K, Ju L, Liu X, Xiao Y, Wang X. Fatty acid oxidation inhibitor etomoxir suppresses tumor progression and induces cell cycle arrest via PPARgamma-mediated pathway in bladder cancer. Clin Sci (Lond). 2019;133(15):1745-58.

23. Cao R, Wang G, Qian K, Chen L, Ju L, Qian G, Wu CL, Dan HC, Jiang W, Wu $M$, et al. TM4SF1 regulates apoptosis, cell cycle and ROS metabolism via the PPARgamma-SIRT1 feedback loop in human bladder cancer cells. Cancer Lett. 2018;414:278-93.

24. Lu M, Ge Q, Wang G, Luo Y, Wang X, Jiang W, Liu X, Wu CL, Xiao Y, Wang X. CIRBP is a novel oncogene in human bladder cancer inducing expression of HIF-1alpha. Cell Death Dis. 2018;9(10):1046.

25. Cheng S, Qian K, Wang Y, Wang G, Liu X, Xiao Y, Wang X. PPARgamma inhibition regulates the cell cycle, proliferation and motility of bladder cancer cells. J Cell Mol Med. 2019;23(5):3724-36.

26. Zhou Q, Chen S, Lu M, Luo Y, Wang G, Xiao Y, Ju L, Wang X. EFEMP2 suppresses epithelial-mesenchymal transition via Wnt/beta-catenin signaling pathway in human bladder cancer. Int J Biol Sci. 2019;15(10):2139-55.

27. Tang Z, Li C, Kang B, Gao G, Li C, Zhang Z. GEPIA: a web server for cancer and normal gene expression profiling and interactive analyses. Nucleic Acids Res. 2017;45(W1):W98-102.

28. Cuylen S, Blaukopf C, Politi AZ, Muller-Reichert T, Neumann B, Poser I, Ellenberg J, Hyman AA, Gerlich DW. Ki-67 acts as a biological surfactant to disperse mitotic chromosomes. Nature. 2016;535(7611):308-12.

29. Zaidi SK, Young DW, Montecino MA, Lian JB, van Wijnen AJ, Stein JL, Stein GS. Mitotic bookmarking of genes: a novel dimension to epigenetic control. Nat Rev Genet. 2010;11(8):583-9.

30. Kumagai A, Dunphy WG. Purification and molecular cloning of Plx1, a Cdc25-regulatory kinase from Xenopus egg extracts. Science. 1996;273(5280):1377-80.
31. Abbas T, Dutta A. p21 in cancer: intricate networks and multiple activities. Nat Rev Cancer. 2009;9(6):400-14.

32. Brabletz T, Kalluri R, Nieto MA, Weinberg RA. EMT in cancer. Nat Rev Cancer. 2018;18(2):128-34.

33. Macurek L, Lindqvist $A$, Lim D, Lampson MA, Klompmaker R, Freire R, Clouin C, Taylor SS, Yaffe MB, Medema RH. Polo-like kinase-1 is activated by aurora A to promote checkpoint recovery. Nature. 2008;455(7209):119-23.

34. Jang YJ, Ma S, Terada Y, Erikson RL. Phosphorylation of threonine 210 and the role of serine 137 in the regulation of mammalian polo-like kinase. J Biol Chem. 2002;277(46):44115-20.

35. Seki A, Coppinger JA, Jang CY, Yates JR, Fang G. Bora and the kinase Aurora a cooperatively activate the kinase Plk1 and control mitotic entry. Science. 2008;320(5883):1655-8.

36. Chan EH, Santamaria A, Sillje HH, Nigg EA. Plk1 regulates mitotic Aurora A function through betaTrCP-dependent degradation of hBora. Chromosoma. 2008;117(5):457-69.

37. Thomas Y, Cirillo L, Panbianco C, Martino L, Tavernier N, Schwager F, Van Hove L, Joly N, Santamaria A, Pintard L, et al. Cdk1 phosphorylates SPAT-1/ Bora to promote PIk1 activation in C. elegans and human cells. Cell Rep. 2016;15(3):510-8

38. Lee YC, Liao PC, Liou YC, Hsiao M, Huang CY, Lu PJ. Glycogen synthase kinase 3 beta activity is required for hBora/Aurora A-mediated mitotic entry. Cell Cycle. 2013;12(6):953-60.

39. Dongre A, Weinberg RA. New insights into the mechanisms of epithelialmesenchymal transition and implications for cancer. Nat Rev Mol Cell Biol. 2019;20(2):69-84.

40. Lens SM, Voest EE, Medema RH. Shared and separate functions of polo-like kinases and aurora kinases in cancer. Nat Rev Cancer. 2010;10(12):825-41.

\section{Publisher's Note}

Springer Nature remains neutral with regard to jurisdictional claims in published maps and institutional affiliations.
Ready to submit your research? Choose BMC and benefit from:

- fast, convenient online submission

- thorough peer review by experienced researchers in your field

- rapid publication on acceptance

- support for research data, including large and complex data types

- gold Open Access which fosters wider collaboration and increased citations

- maximum visibility for your research: over $100 \mathrm{M}$ website views per year

At BMC, research is always in progress.

Learn more biomedcentral.com/submissions 